\title{
The role of intermittent negative pressure wound therapy combined with a mesh incision in the salvage of perforator flap with venous congestion, a case report
}

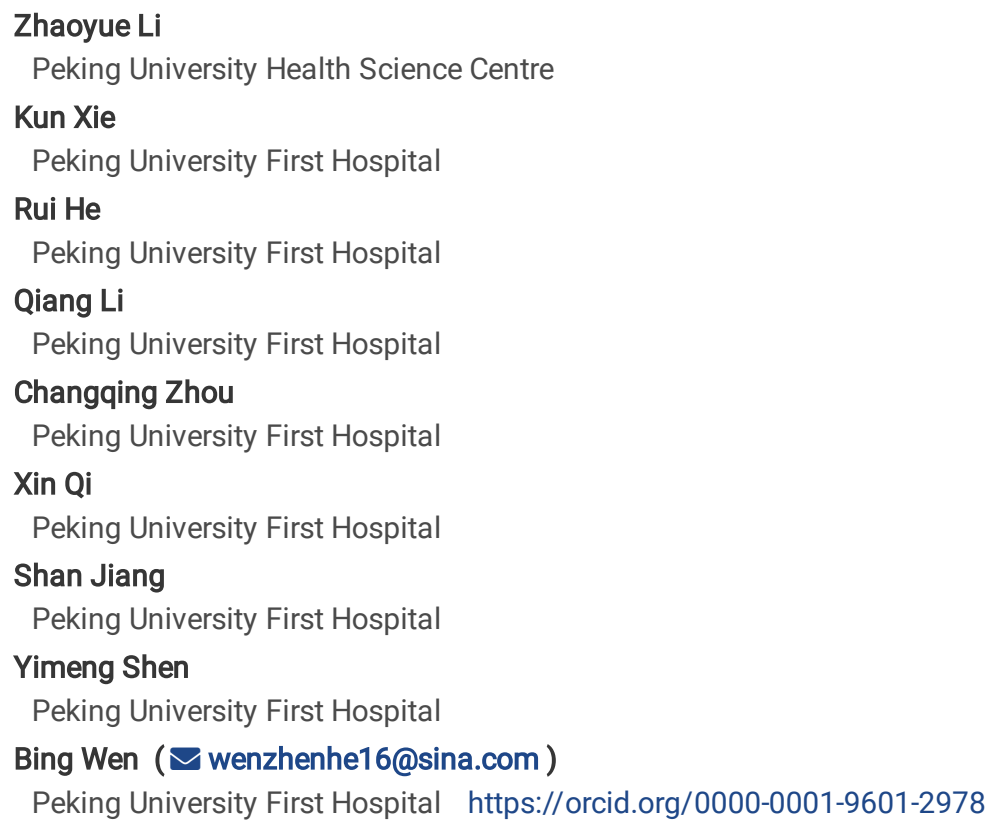




\section{Abstract}

Background: The application of perforator flap is becoming wide. The most common postoperative complication is venous congestion but traditional treatments' effect is limited. A new method called negative pressure wound therapy(NPWT) was introduced to improve wound healing. Many scholars have tried this method with continuous mode and achieved good outcomes. In this paper, we tried a different mode(intermittent) of negative pressure wound therapy on congested perforator flaps after a mesh incision, and we expected this paper could provide information for follow-up clinical research.

Case presentation: A retrospective research of 6 patients (6 perforator flaps) who had been suffered from venous congestion from June, 2016 to June, 2019 was performed. All flaps were treated by intermittent negative pressure wound therapy after a mesh incision. Among 6 flaps, 4 of them were totally survived while the other 2 of them were mostly survived.

Conclusions: Intermittent negative pressure wound therapy combined with a mesh incision can be a safe option to rescue perforator flaps with venous congestion. This technique has a certain success rate and clinical application value.

\section{Introduction}

The application of perforator flap is becoming common in reconstruction surgeries. Koshima and Soedain first come up with this concept in 1989(1). They used a flap with no muscle instead of the traditional musculocutaneous flap, which turned out to be a great combination of the reliability and vascular security of musculocutaneous flaps with lower donor-site morbidity of simple cutaneous flaps(2). However, because perforator flap is only supplied by small-diameter perforators, the rotation and shaping of the flap, along with postoperative tissue edema and blood clot accumulation may cause the pedicle to twist, stretch or oppress. These factors affect the local blood flow of the pedicle, which leads to vessel complications.

The most common postoperative complication is venous congestion. Traditional treatments mainly include surgical exploration, anticoagulants injection, blood-letting method, leeching therapy, whose effect however, is limited, and flap necrosis is mostly inevitable.

A new method called negative pressure wound therapy(NPWT) was introduced to improve wound healing by Morykwas and Argenta in 1997(3). This technique, once was named as vacuum assisted closure(VAC), consists of placing an open-cell foam into the wound area, sealing the site with an adhesive material, and applying negative pressure $(-125 \mathrm{mmHg})$ that is transmitted to the wound in a controlled mode. Researchers have confirmed that this method can improve angiogenesis and transformation by increasing tissue perfusion, capillary caliber and blood volume(4), in which way, helping with wound healing. In this paper, we tried to apply intermittent NPWT on perforator flaps with venous congestion after a mesh incision was done on the affected area, and we found it might be an effective and safe method considering such issues.

\section{Patients And Methods}

We retrospectively analyzed the clinical information of 6 cases who were affected by venous congestion after perforator flap reconstructions in Peking University First Hospital from June, 2016 to June, 2019. Our diagnosis of venous congestion referred to signs including cyanotic skin color, cool temperature $\left(\triangle 2^{\circ} \mathrm{C}\right.$ of difference compared to control), rapid capillary refill, increased tissue turgor, and rapid dark bleeding in response to a puncture $(5,6)$. When a venous congestion was noticed, we explored the perforator immediately by doing a mesh incision to exclude mechanical obstruction such as blood accumulation underneath or venous thrombosis, and factors that affected the artery flow. After that, we applied intermittent NPWT on the affected flap. The following parameters were recorded: defect and localization, etiology of defect, size and kind of perforator flaps, occurrence time of venous congestion, timing of NPWT application, NPWT duration, and survival ratio.

\section{Case Presentation}

Information of 5 females and 1 male with an average age of 54.2-year-old (32-68) is listed in Table 1. 2 cases had defects in the upper limb while 1 case in the lower limb, 2 cases in trunk, and 1 case in sacrococcygeal area. As for perforator flaps, 2 intercostal artery perforator flaps, 1 superior gluteal artery perforator flap, 1 upper limb perforator flap, 1 lower limb perforator flap and 1 free anterior lateral femoral flap were applied respectively. The approximate size of flaps ranged from $10 \mathrm{~cm} \times 5 \mathrm{~cm}$ to $20 \mathrm{~cm} \times 7 \mathrm{~cm}$. The occurrence time of venous congestion ranged from $36 \mathrm{~h}$ to $96 \mathrm{~h}$ post-surgery.

Among the 6 flaps, 4 of them survived completely while 2 others were mostly conserved. Only small part of distal area remained unhealed in these 2 cases, which, were sutured under local infiltration anesthesia or covered with free skin flap after debridement respectively. Both of them were healed after. No complications were found during 3 months' follow-up of the flaps: the shape of the flaps was almost normal, with no obvious edema or scar contracture. As for patients, all of them were basically satisfied with the ultimate appearance and fundamental function of the flap. 
Table 1

Characteristics of the Patients

\begin{tabular}{|c|c|c|c|c|c|c|c|c|c|c|}
\hline NO & Gender & Age & $\begin{array}{l}\text { Defect and } \\
\text { location }\end{array}$ & Etiology & $\begin{array}{l}\text { Perforator } \\
\text { flap }\end{array}$ & $\begin{array}{l}\text { Size } \\
(\mathrm{cm} \\
\mathbf{x} \\
\mathrm{cm})\end{array}$ & $\begin{array}{l}\text { Occurrence } \\
\text { time(h) }\end{array}$ & $\begin{array}{l}\text { Area of } \\
\text { venous } \\
\text { congestion }\end{array}$ & Duration(d) & Result \\
\hline 1 & Female & 68 & Right palm & Melanoma & $\begin{array}{l}\text { Ulnar artery } \\
\text { dorsal } \\
\text { carpal } \\
\text { branch } \\
\text { perforator }\end{array}$ & $\begin{array}{l}15 \\
\times 6\end{array}$ & 48 & Whole & 9 & Survival \\
\hline 2 & Female & 66 & Chest wall & Keloid & $\begin{array}{l}\text { Sixth } \\
\text { intercostal } \\
\text { perforator }\end{array}$ & $\begin{array}{l}15 \\
\times 6\end{array}$ & 36 & Whole & 12 & $80 \%$ survival \\
\hline 3 & Female & 32 & Right forearm & Keloid & $\begin{array}{l}\text { Free } \\
\text { anterolateral } \\
\text { thigh } \\
\text { perforator }\end{array}$ & $\begin{array}{l}14 \\
\times 9\end{array}$ & 96 & Distal1/2 & 12 & $75 \%$ survival \\
\hline 4 & Female & 58 & $\begin{array}{l}\text { Sacrococcygeal } \\
\text { region }\end{array}$ & $\begin{array}{l}\text { Pleomorphic } \\
\text { undifferentiated } \\
\text { sarcoma }\end{array}$ & $\begin{array}{l}\text { Superior } \\
\text { gluteal } \\
\text { artery } \\
\text { perforator }\end{array}$ & $\begin{array}{l}20 \\
\times 7\end{array}$ & 72 & Distal1/2 & 6 & Survival \\
\hline 5 & Female & 39 & Right heel & Melanoma & $\begin{array}{l}\text { Posterior } \\
\text { tibial artery } \\
\text { perforator }\end{array}$ & $\begin{array}{l}10 \\
\times 7\end{array}$ & 48 & Distal1/3 & 6 & Survival \\
\hline 6 & Female & 62 & Chest wall & Radiation ulcer & $\begin{array}{l}\text { Second } \\
\text { intercostal } \\
\text { perforator }\end{array}$ & $\begin{array}{l}10 \\
\times 5\end{array}$ & 48 & Distal1/4 & 6 & Survival \\
\hline
\end{tabular}

\section{NPWT method}

First of all, a mesh incision was made on the skin of the affected. This kind of mesh cut contained multiple incisions that had a length less than $1 \mathrm{~cm}$ and deeply passed through epidermis and dermis, parallel to the direction of flap's venous flow (Fig. 1-B). This procedure provided surgeons with an observation window, through which we could examine the color of blood and fat, and the fluid flow velocity, to determine if there was any mechanical factors or necrosis underneath. In addition, diagnosis of venous congestion could be double assured by the sign of rapid dark bleeding from cutting.(5)After that, the NPWT was applied as a salvage therapy over the congested area (Fig. 2-B), sparing the pedicle area as an observation window to monitor the skin color and temperature, from which we could notice if any other complications such as artery issues once happened. Intermittent negative pressure $(-125 \mathrm{mmHg})$ was applied. This mode consists of 5 minutes of $-125 \mathrm{mmHg}$ pressure, followed by 2 minutes of $0 \mathrm{mmHg}$ pressure. The sterilized foam placed in the wound was changed every $72 \mathrm{~h}$ or depended on wound discharge. Duration of this therapy ranged from 6 to 12 days. Doctors evaluated the viability of the flap every day through clinical observation and puncture test around the pedicle area.

\section{Discussion And Conclusions}

Clinical application of perforator flaps has gradually become popular in reconstruction surgeries since proposed in 1989(1). The perforator flap refers to a kind of flap that is vascularized by small-diameter vessels which passes either through or in between the deep tissues (mostly muscle) (7). It belongs to the category of axial vascular flaps. The application conforms to the principle of tissue transplantation-"well repair of recipient site, less damage to donor site". This kind of flap has the advantage of flexible design and fast recovery, which makes it suitable for the reconstruction of tissue defects. It is widely used in various repair and reconstruction operations to achieve a better aesthetic appearance and physiological function. As the number of flap operations keeps increasing, flap extraction and transfer techniques are improving continuously, though blood flow dysfunction still remains the most common postoperative complication-up to 7\% according to Salvatore, et al(8). Improper treatment may eventually lead to flap ischemic necrosis. The causes of postoperative blood flow dysfunction include arterial, venous, and microcirculation. Arterial compromise is a situation that progresses rapidly. It is more harmful than venous congestion and must be dealt with urgently. In contrast, venous crisis is relatively easier to identify and progresses more slowly, also the affected tissue may have a greater survival rate. The main reasons for venous failure are mechanical obstruction, anatomical variation, or technical errors due to inadequate length pedicle, inadequate venous drainage, compression and kinking of the vein(9). The occurrence of venous congestion is due to insufficient venous return, resulting in stasis in the affected flap, which leads to platelet and fibrinogen accumulation and microcirculation intravascular thrombosis(10). All of these changes in microcirculation may persist even after the mechanical obstruction is relieved. If not treated in time, it will occlude the capillaries and inflow arteries. Ischemic necrosis will be inevitable. In these cases, reconstruction of physiological venous outflow is essential to avoid continuous pathophysiologic changes in microcirculation. Once the mechanical obstruction is lifted, different non-surgical methods could be 
used as salvage treatments for congested flaps, such as anticoagulant therapy (heparin and prostaglandin E1), manual massage to encourage drainage of the congested blood, placement of external catheters for venous drainage, subcutaneous injection of low-molecular-weight heparin or recombinant tissue plasminogen activator, blood-letting with intermittent needle puncture, and the prescription of medical leeches(11). However, the salvage rate of non-surgical methods above is less than $80 \%$ according to $\mathrm{Yu}$, et al(11).

In recent years, NPWT has been increasingly used for wounds since it was first come up with in 1997 by Morykwas and Argenta. They presented the conclusion that $125 \mathrm{mmHg}$ subatmospheric pressure could increase the blood flow fourfold and decrease tissue bacterial count with an animal based experiment, both continuously and intermittently(3). Up to date studies have pointed out that NPWT promotes wound healing mainly from two aspects, fluid-based and mechanical way(12). It increases tissue perfusion and improve microcirculation by increasing capillary caliber and density $(4,13)$. The existence of mechanical forces, as well as change in endothelial morphology and increase in blood flow stimulates endothelial proliferation, capillary budding and angiogenesis(14), promoting granulation tissue formation(13). Previous studies also have shown that NPWT may promote the formation of small blood vessels by changing the microstructure of capillaries and endothelial cells, promoting the vitality of flaps, and thereby increase blood flow reversely(15). Moreover, scholars have found that negative pressure creates a hypoxia-sensitive environment, which promotes the early nonspecific immunity of neutrophils(16) in the inflammatory phase and increases tendency of collagen formation(17) in the proliferation phase. Besides, it also promotes collagen fiber production and increase the tensile strength and stability of wounds, substantially promoting the whole process of healing. On the other side, continuous drainage by NPWT can reduce the occurrence of hematoma and effusion in order to eliminate dead space and reduce infection by reducing excess interstitial fluid(18). This physically results in a decrease in interstitial pressure, which helps the capillaries reopen and restores the flow around(12). Drainage of fluid also reduce bacteria colonization, avoiding wound infections. An animal based study pointed out that the application of NPWT in patients who had a higher risk of incision dehiscence, nonunion and infection could reduce the occurrence of postoperative complications and help incision healing(13). Another randomized controlled study(18) has confirmed on patients that an increase in skin perfusion could be noted on day 5 of NPWT treatment, allowing earlier removal of drains and enhancing the skin perfusion on the repaired skin, which significantly reduced the amount of fluid collected, and more importantly, complications and days of hospital stay.

Techniques regarding NPWT have been developing, though the way of applying is still unsettled, especially on its mode. Series of trials have confirmed that the external pressure exerted by NPWT can mechanically squeeze the stagnated venous blood and tissue fluid to relieve congestion and edema, but may also cause arterial ischemia(19). These findings arose novel ways of application, such as lower magnitude(20), delayed setting(21), sparing the pedicle part(22), etc. In our cases, we choose to apply the NPWT over the congested area, sparing the pedicle area as an observation window to monitor the skin color and temperature, so that we could notice if any other complications happened such as artery insufficiency. As for NPWT modes, according to literatures, continuous mode still remains priority in the application of NPWT considering wound therapy. However, Morykwas and Argenta found an increase in granulation tissue formation in both continuous and intermittent application but a more rapid deposition in the latter one( $\mathrm{p} \leq 0.01)(3)$, although in an animal based study in 2013 , Kangwoo N Lee, et al found all NPWT modes despite of continuous, intermittent or cyclic showed more reduction in wound volume compared with the no-pressure group and there was no statistical significance (23). In 2018, A. Sogorski, et al supplemented this conclusion by measuring local pressure to the underlying tissue and microcirculatory changes such as blood flow, oxygen saturation, relative hemoglobin content and red blood cell velocity on 2 intermittent suctions. Their results supported that repetitive triggering brought by intermittent NPWT mode could enhance the fundamental physiologic response to induced shear-stress, which promoted the release of growth factors(24) and therefore increase granulation tissue formation, compared to continuous mode with single triggering $(12,25)$. Hence, it is obvious that intermittent mode is taking over more stage on wound therapy. It contains a suction part along with a release part and repeats as settled. In the suction part, drainage by NPWT appears as one of the major effective factors among others while in the subsequent part, releasing of tissue allows oxygen-rich blood from artery to nourish the flap. A recent study showed that blood flow rose over time in intermittent mode and even sustained after the last suction ended. Researchers assumed that a compressed vasculature post-occlusive reactive hyperemia (PORHA), also known as reactive hyperemia might be an explanation for the increase in perfusion after suction was turned off $(25,26)$. Therefore, in our cases, we tried to apply NPWT on perforator flaps with venous congestion in an intermittent mode, which turned out to be an effective treatment.

Many scholars have found that NPWT has a good therapeutic effect on venous congestion after flap operation. Vaienti, et al applied NPWT on pedicle and free flaps for reconstruction of lower limbs after trauma. After NPWT removal, viable granulation tissue was observed and the wound could be treated with a partial- thickness skin graft in all cases(27). Qiu, et al used NPWT as a salvage method on pedicle and free-flaps on multiple reconstructions including defects after tumor, defects with prosthesis or bone exposure, and chronic wounds. They removed the furthest stitches and applied NPWT on a raw surface. As a result, all flaps survived(20). Uygur, et al saved an anterolateral thigh fasciocutaneous flap with two cycles of VAC therapy-an early version of NPWT, in which case venous congestion disappeared mostly 72 hours later(22). However, none of the above have ever reported NPWT application along with mesh incisions on the perforator flap with venous congestion. Referring to literatures reported, we decided to apply NPWT on flaps threatened by venous congestion, as soon as a sign of compromise was noted and right after exploration was done. At present, the selection of NPWT pressure is still not unified, ranging from $-50 \mathrm{mmHg}$ to $-150 \mathrm{mmHg}$, and the treatment mode is mainly continuous while some researchers also use intermittent treatment mode(11). Our current plan is intermittent treatment with a $-125 \mathrm{mmHg}$ pressure. The choice of treatment mode and pressure should be further studied. And as a salvage treatment, considering flap perfusion 
under negative pressure might increase around 5 days, we decided to apply NPWT for at least 5 days, also depending on the improvement of congestion.

As a salvage treatment for post-surgery complications including flap venous congestion, NPWT plays an important role with a high success rate of $96.9 \%(11)$. Although, we still consider prevention as the first priority. Before surgery, radiological examination like CTA or MRA is recommended if possible. Studies have shown that preoperative CTA can identify atypical venous connections between deep and superficial systems that increase the risk of postoperative congestion five-fold(28). Identifying atypical venous connections maximizes the chances of flap survival and minimizes complications. Besides, comorbidities like diabetes, hypertension disease, peripheral vascular disease, hypoproteinemia, anemia, etc. should be evaluated before. During the operation, surgeons should dissect the vascular pedicle completely and avoid pulling or shearing during the transfer and rotation of the flap, which may affect the blood supply of the flap. Also, precise operation is needed, to reduce damage around the vascular pedicle. When the surgery is finished, doctors and nurses should provide expert intensive care in the early postoperative period: monitor if any oozing of dusky blood occurs, notice any changes in skin color and temperature, check the blood flow by puncture tests, and take photos regularly if possible(20).

Current diagnosis of venous congestion mainly depends on clinical evidence including cyanotic skin color, cool temperature $\left(\varangle 2^{\circ} \mathrm{C}\right.$ of difference compared to control), rapid capillary refill, increased tissue turgor, and rapid dark bleeding in response to a puncture(5, 6). Once a venous issue occurs, early treatment is of great urgency. Doctors should exclude mechanical obstruction such as hematoma under the flap and venous thrombosis or any other possible factors by surgical intervention. If the obstruction is not relieved, the blood supply of the skin flap is difficult to recover. We have also tried to use NPWT in patients with failed recanalization of venous thrombosis, but none of them were successful. However, contraindications of surgical intervention do exist at some point. Examples are, venous compromise after propeller flap reconstruction with sizeable perforators; venous congestion after dividing the skin bridge in pedicle flaps; venous congestion after non-physiological flap reconstructions; and other patient conditions for which surgical intervention is contraindicated, such as patient's severe comorbidities, refusal of further surgeries, or tortuous venous anatomy(20). In our cases, we used a mesh incision as an exploration and observation method. Short cuts through full-thickness skin created an observation window from which we could carefully determine whether the blood color was bright red or dull and the fat tissue necrosis or not to evaluate the circulation under the skin. This procedure is similar to blood-letting method, which has been a mature treatment for venous stasis(11). We combined this method with NPWT here was because besides checking the blood circulation, this kind of mesh incision that aimed for blood-letting also had a function of skin tension releasing. It allowed off-loading releasing without removing the suture between flap and recipient site, which ensured the fixation of flap and accelerated healing, shortening hospital stay. It increased the area of fluid drainage, helping release of tissue edema, moreover, it also ensured a sufficient contact area between NPWT device and wound bed, which was vital since we expected the negative pressure could transmit into the deep structure to fully develop it capacity.

In conclusion, intermittent NPWT can be used as a non-surgical treatment for patients with venous congestion with a high success rate and few complications. A mesh incision before may help with observing and tension releasing. We believe that early application of NPWT along with a mesh incision may improve the survival rate of the flap. However, patient's discomfort should be taken into consider since it may influence patient's compliance for the treatment, thereby affect the efficacy of this method. It is also necessary to determine the effectiveness in further clinical practices such as different implementations on specific kinds of flaps. Moreover, mechanism in this process, contraindications and personalized mode needs further study.

\section{Declarations}

\section{Ethics approval and consent to participate}

Ethical approval is not required since this is a case report that only involves medical records of anonymous patients and does not include any identification data. No procedures were aimed for study purpose.

\section{Consent for publication}

Written informed consent for publication was obtained from all participants

\section{Availability of data and materials}

All data and materials are presented in the paper.

\section{Competing interest and funding}

The authors declare that they have no competing interests or funding for this paper.

\section{Contributions and consent for publication}


LZY drafted the manuscript; designed the case report. XK, HR, HS, SYM, collected clinical information. LQ, QX, ZCQ, WB instructed and revised the manuscript. All authors read and approved the final manuscript.

\section{Acknowledgements}

Not applicable.

\section{Authors information}

Dr. Zhaoyue Li, Peking University Health Science Centre, lizhaoyuedy@163.com

Dr. Kun Xie, Peking University First Hospital, drxiekun@126.com

Dr. Rui He, Peking University First Hospital, disandiguoherui@163.com

Dr. Qiang Li, Peking University First Hospital, 330350514@qq.com

Dr. Changqing Zhou, Peking University First Hospital, zzz707070@126.com

Dr. Xin Qi, Peking University First Hospital, randyq@126.com

Dr. Shan Jiang, Peking University First Hospital, jiangshan_an_beijing@163.com

Dr. Yimeng Shen, Peking University First Hospital, yimeng_ng_shen@163.com

Dr. Bing Wen, Peking University First Hospital, wenzhenhe16@sina.com

\section{Abbreviations}

NPWT-negative pressure wound therapy

\section{References}

1. Koshima I, Soeda S. Inferior epigastric artery skin flaps without rectus abdominis muscle. Br J Plast Surg. 1989;42(6):645-8.

2. Kroll SS, Rosenfield L. Perforator-based flaps for low posterior midline defects. Plastic reconstructive surgery. 1988;81(4):561-6.

3. Morykwas MJ, Argenta LC, Shelton-Brown El, McGuirt W. Vacuum-assisted closure: a new method for wound control and treatment: animal studies and basic foundation. Ann Plast Surg. 1997;38(6):553-62.

4. Chen SZ, Li J, Li XY, Xu LS. Effects of vacuum-assisted closure on wound microcirculation: an experimental study. Asian J Surg. 2005;28(3):211-7.

5. Daane S. Chapter 111 - Leeches. In: Weinzweig J, editor. Plastic Surgery Secrets Plus (Second Edition). Philadelphia: Mosby; 2010. p. 721-3.

6. Zamboni WA, Baynosa RC. Chapter 17 - Compromised Grafts and Flaps. In: Neuman TS, Thom SR, editors. Physiology and Medicine of Hyperbaric Oxygen Therapy. Philadelphia: W.B. Saunders; 2008. pp. 373-95.

7. Blondeel PN, Van Landuyt KHI, Monstrey SJM, Hamdi M, Matton GE, Allen RJ, et al. The "Gent" consensus on perforator flap terminology: preliminary definitions. Plastic and reconstructive surgery. 2003;112(5).

8. D'Arpa S, Cordova A, Pignatti M, Moschella F. Freestyle pedicled perforator flaps: safety, prevention of complications, and management based on 85 consecutive cases. Plastic reconstructive surgery. 2011;128(4):892-906.

9. Schaverien MV, Ludman CN, Neil-Dwyer J, Perks AG, Raurell A, Rasheed T, et al. Relationship between venous congestion and intraflap venous anatomy in DIEP flaps using contrast-enhanced magnetic resonance angiography. Plast Reconstr Surg. 2010;126(2):385-92.

10. Hjortdal VE, Sinclair T, Kerrigan CL, Solymoss S. Venous ischemia in skin flaps: microcirculatory intravascular thrombosis. Plastic reconstructive surgery. 1994;93(2):366-74.

11. Yu P, Yu N, Yang X, Jin X, Lu H, Qi Z. Clinical Efficacy and Safety of Negative-Pressure Wound Therapy on Flaps: A Systematic Review. J Reconstr Microsurg. 2017;33(5):358-66.

12. Morykwas MJ, Simpson J, Punger K, Argenta A, Kremers L, Argenta J. Vacuum-assisted closure: state of basic research and physiologic foundation. Plastic reconstructive surgery. 2006;117(7 Suppl):121S-6S.

13. Suh H, Lee AY, Park EJ, Hong JP. Negative Pressure Wound Therapy on Closed Surgical Wounds With Dead Space: Animal Study Using a Swine Model. Ann Plast Surg. 2016;76(6):717-22.

14. Vandenburgh HH. Mechanical forces and their second messengers in stimulating cell growth in vitro. Am J Physiol. 1992;262(3 Pt 2):R350-R5. 
15. Malmsjö M, Ingemansson R. Effects of green foam, black foam and gauze on contraction, blood flow and pressure delivery to the wound bed in negative pressure wound therapy. J Plast Reconstr Aesthet Surg. 2011;64(12):e289-e96.

16. Hunt TK, Hopf HW. Wound healing and wound infection. What surgeons and anesthesiologists can do. Surg Clin North Am. 1997;77(3):587606.

17. Prockop DJ, Kivirikko Kl, Tuderman L, Guzman NA. The biosynthesis of collagen and its disorders (first of two parts). N Engl J Med. 1979;301(1):13-23.

18. Peter Suh H-S, Hong JP. Effects of Incisional Negative-Pressure Wound Therapy on Primary Closed Defects after Superficial Circumflex Iliac Artery Perforator Flap Harvest: Randomized Controlled Study. Plastic reconstructive surgery. 2016;138(6):1333-40.

19. Kairinos N, Voogd AM, Botha PH, Kotze T, Kahn D, Hudson DA, et al. Negative-pressure wound therapy II: negative-pressure wound therapy and increased perfusion. Just an illusion? Plastic reconstructive surgery. 2009;123(2):601-12.

20. Qiu SS, Hsu C-C, Hanna SA, Chen SH-Y, Cheong C-F, Lin C-H, et al. Negative pressure wound therapy for the management of flaps with venous congestion. Microsurgery. 2016;36(6):467-73.

21. Yang Y-H, Jeng S-F, Hsieh C-H, Feng G-M, Chen CC. Vacuum-assisted closure for complicated wounds in head and neck region after reconstruction. J Plast Reconstr Aesthet Surg. 2013;66(8):e209-e16.

22. Uygur F, Duman H, Ulkür E, Ceiköz B. The role of the vacuum-assisted closure therapy in the salvage of venous congestion of the free flap: case report. Int Wound J. 2008;5(1):50-3.

23. Lee KN, Ben-Nakhi M, Park EJ, Hong JP. Cyclic negative pressure wound therapy: an alternative mode to intermittent system. Int Wound J. 2015;12(6):686-92.

24. Chen KD, Li YS, Kim M, Li S, Yuan S, Chien S, et al. Mechanotransduction in response to shear stress. Roles of receptor tyrosine kinases, integrins, and Shc. J Biol Chem. 1999;274(26):18393-400.

25. Sogorski A, Lehnhardt M, Goertz O, Harati K, Kapalschinski N, Hirsch T, et al. Improvement of local microcirculation through intermittent Negative Pressure Wound Therapy (NPWT). J Tissue Viability. 2018;27(4):267-73.

26. Wilkin JK. Periodic cutaneous blood flow during postocclusive reactive hyperemia. Am J Physiol. 1986;250(5 Pt 2):H765-H8.

27. Vaienti L, Gazzola R, Benanti E, Leone F, Marchesi A, Parodi PC, et al. Failure by congestion of pedicled and free flaps for reconstruction of lower limbs after trauma: the role of negative-pressure wound therapy. J Orthop Traumatol. 2013;14(3):213-7.

28. Davis CR, Jones L, Tillett RL, Richards H, Wilson SM. Predicting venous congestion before DIEP breast reconstruction by identifying atypical venous connections on preoperative CTA imaging. Microsurgery. 2019;39(1):24-31.

\section{Figures}



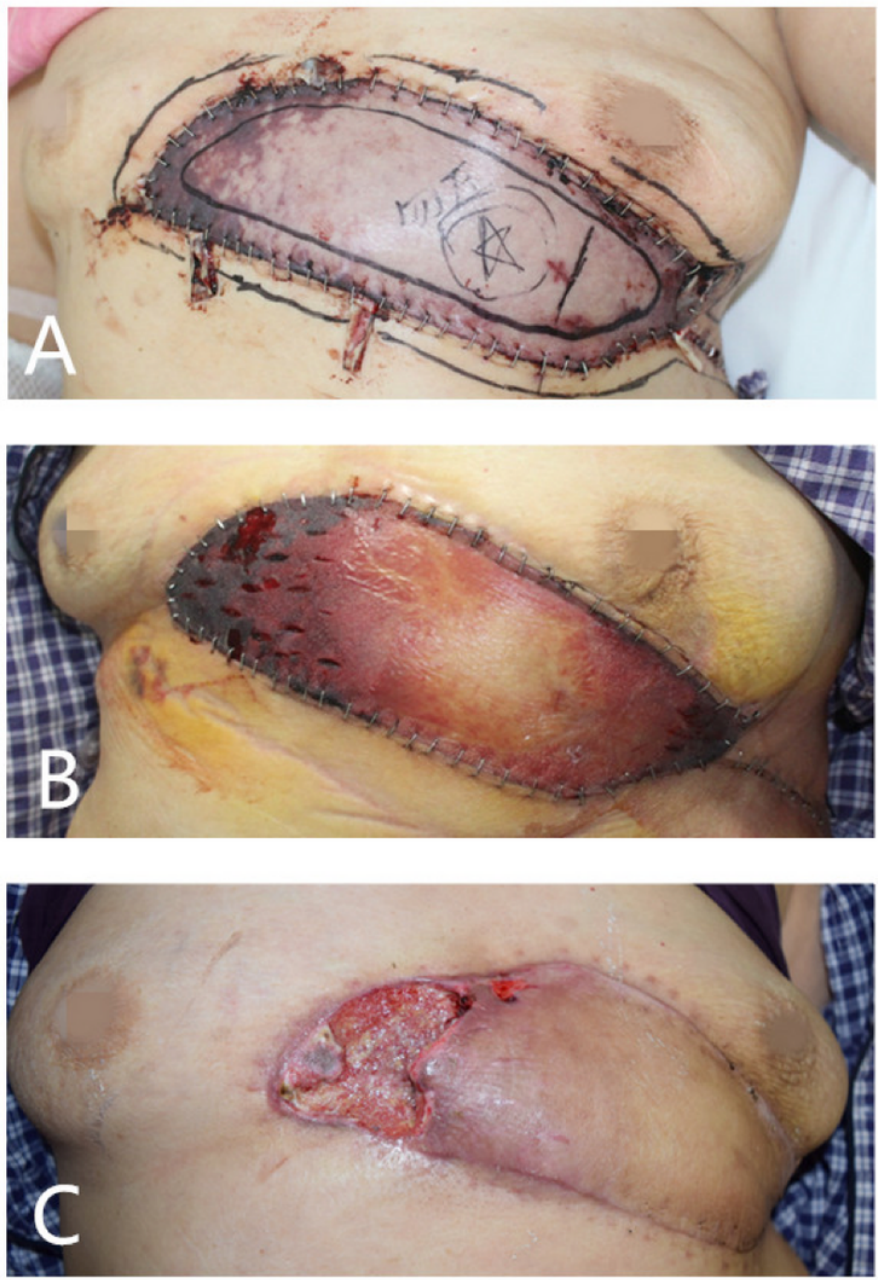

\section{Figure 1}

A) Venous congestion occurred 36 hours after the left sixth intercostal perforator flap was transferred to repair a chest wall keloid; B) the flap appearance after 6 days of negative pressure treatment with a surgical exploration to exclude obstruction before applied; C) skin flap appearance after 12 days of negative pressure treatment, and $20 \%$ of distal skin flap necrosis occurred. 

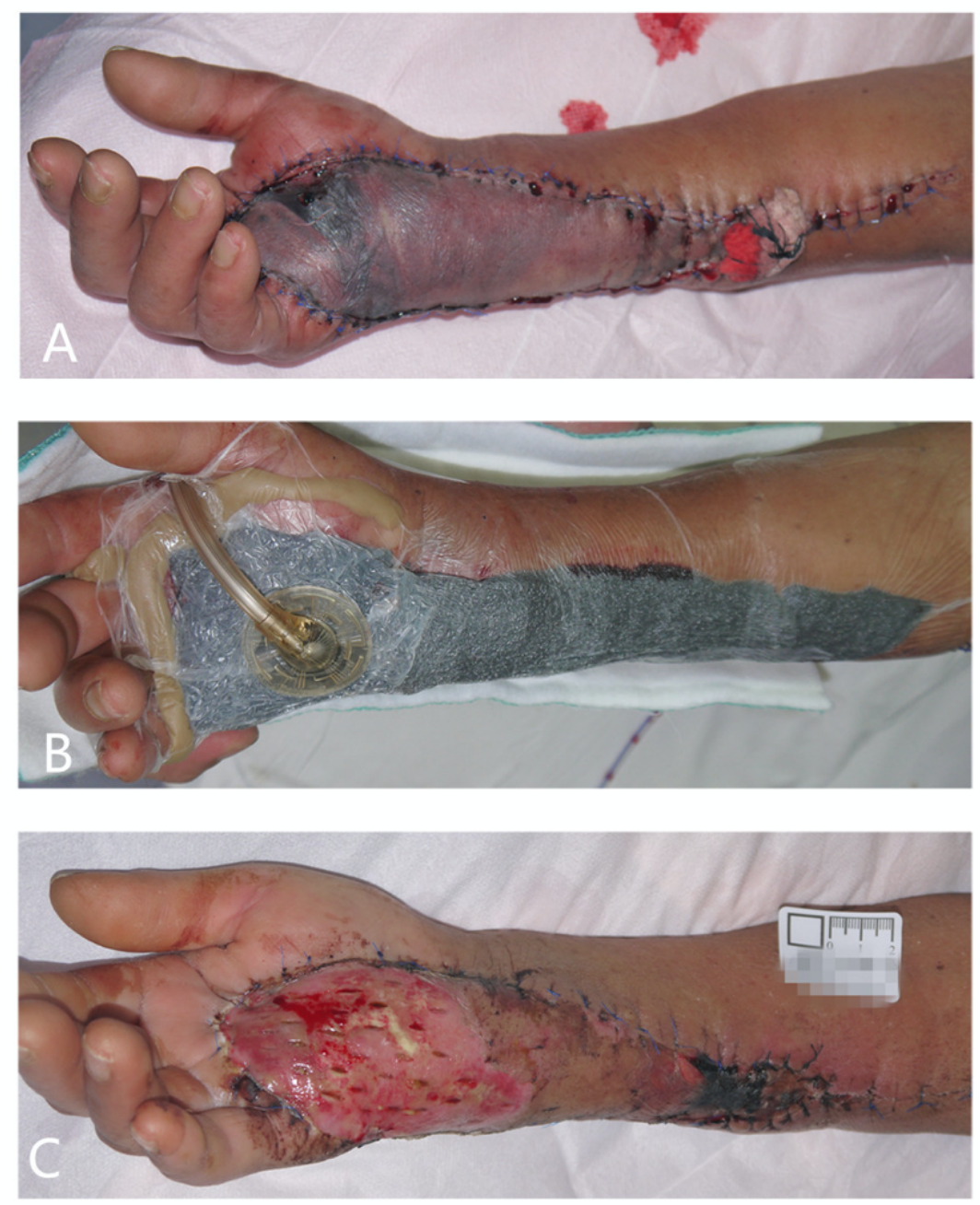

\section{Figure 2}

A) Venous congestion occurred 48 hours after operation of ulnar artery perforator flap after the resection of malignant melanoma of palm; B) flap was treated with external negative pressure after mechanical obstruction was excluded; C) flap was completely survived after 9 days of treatment. 